\title{
Auto-avaliação: uma alternativa contemporânea do processo avaliativo
}

\author{
Kleber Aparecido da Silva \\ Universidade Estadual Paulista - UNESP - São José do Rio Preto \\ Maria Amélia Nader Bartholomeu \\ Universidade São Francisco - USF \\ Universidade Estadual de Campinas - UNICAMP \\ Maristela M. Kondo Claus \\ Universidade São Francisco - USF \\ Universidade Estadual de Campinas - UNICAMP
}

\begin{abstract}
A auto-avaliação, segundo as pesquisas, tem se mostrado um excelente auxiliar para o processo de ensino/aprendizagem em sala de aula, como mecanismo diagnóstico, para que professores e alunos tenham uma visão mais clara de suas potencialidades. Este artigo, portanto, tem como objetivo apresentar as diferentes alternativas de auto-avaliação, seus objetivos e suas restrições, além de estudos bem-sucedidos em que foram utilizados esse instrumento avaliativo, à luz de teorias nas áreas de Educação e Lingüística Aplicada.
\end{abstract}

According to some researches, self-assessment has played a very important role as a support to teaching/learning process in classroom environment as a diagnostic means to help teachers and students have a better view of their potentialities. Thus, this article aims at showing different alternatives of selfassessment, their objectives, as well as their restrictions, but mainly the successful studies in which this way of alternative assessment was used. This research was based on theories of Educational and Applied Linguistics areas.

A auto-avaliação informal é uma parte natural da aprendizagem de línguas. A auto-avaliação formal deve ajudar a enfocar a atenção dos aprendizes em suas potencialidades, fraquezas e necessidades futuras. Se empregada continuamente durante um curso, a auto-avaliação tem se mostrado de grande valor tanto para o professor quanto para o aluno.

(LEWIS, 1990 apud BAILEY, 1998). 


\section{Introdução}

Embora haja um reconhecimento por parte de alguns professores da importância da avaliação, Scaramucci (1997, p. 76) afirma que, na prática, eles ainda apresentam modelos estruturados em antigos paradigmas. Como alternativa para a prática da avaliação autoritária, que marca o modelo de avaliação hoje existente, Luckesi (1996, p. 32), propõe que a avaliação seja um mecanismo diagnóstico da situação, para que avanços sejam alcançados e para fazer face às pedagogias cujo foco é a participação democrática de todos, de forma igualitária, que só se dará a partir da conquista da autonomia e da reciprocidade das relações.

As novas tendências no ensino de línguas trouxeram uma nova concepção de linguagem, de ensinar/aprender e de avaliar; dessa forma, o ensino centrado no aluno, como desenvolvimento lógico dessas novas tendências, as enriquecem, segundo Hill (1994, p. 214), através da incorporação da participação do aprendiz. Assim, o ensino centrado no aluno pressupõe também a sua autonomia, ou seja, a responsabilidade do próprio aluno por sua aprendizagem, tornando-o, portanto, capaz de se auto-avaliar, administrar e modificar o seu progresso individual (DICKINSON, 1987; CRABBE, 1993).

Uma concepção contemporânea de avaliação pressupõe não só os instrumentos tradicionalmente aplicados para avaliar os alunos, a instituição de ensino e os professores, mas outras formas alternativas de avaliação, ${ }^{1}$ que devem ser, necessariamente, contínuas.

A auto-avaliação, entre essas outras formas, pode alcançar bons resultados, desde que as pessoas envolvidas nesse processo estejam conscientes dos critérios para a sua aplicação: estabelecimento de objetivos gerais e de objetivos específicos para cada questão; clareza quanto às necessidades dos alunos; planejamento bem delineado; e reflexões teóricas a respeito das teorias que subjazem ao processo, pois se a auto-avaliação for utilizada de maneira impressionista, em vez de ser um instrumento de desenvolvimento, poderá se tornar fonte de desentendimento. Entretanto, a sua implementação não é um processo fácil, pois envolve uma

\footnotetext{
${ }^{1}$ Como formas alternativas de avaliação, podemos destacar, além da auto-avaliação, portfólios, entrevista individual, diários dialogados, gravações em vídeo, gravações em áudio, observações do professor, entre outras, que poderão ser negociadas entre professores e alunos.
} 
preparação dentro de uma perspectiva humanista, que, segundo Hill ( $O p$. cit., p. 214), pressupõe responsabilidade pessoal e necessidade de qualquer professor em explorar os aspectos intelectuais e afetivos dos estudantes.

Para Scaramucci (Op.cit.), os objetivos de ensino e da avaliação devem estar sempre relacionados, ou seja, devem estar regidos por uma mesma abordagem. O não estabelecimento de objetivos claros e muito bem explicitados, e de uma preparação prévia tanto de professores quanto de alunos, com relação à auto-avaliação, pode causar conflitos, distanciando a auto-avaliação de seu papel principal, que, segundo Macedo (1998, p. 2), é o de ajudar a criar senso de responsabilidade no aprendiz e levá-lo a exercitar a sua capacidade de autocrítica. Segundo o autor, é comum a divergência entre as opiniões dos alunos sobre si mesmos e as interpretações que os professores têm desses mesmos alunos, transformando a autoavaliação numa batalha de opiniões. Os alunos, por um lado, passam a considerar esse instrumento como um engodo, e os professores, por outro, acreditam que os alunos não estão preparados para emitir quaisquer considerações sobre si mesmos, tornando a auto-avaliação empobrecida e muito distante de seus reais objetivos - ou seja, um elemento para a construção da aprendizagem.

Para melhor compreender e analisar a auto-avaliação, este trabalho está organizado em três seções. Na primeira, apresentaremos a definição e os objetivos gerais da auto-avaliação, fazendo menção às formas de autoavaliação: do aluno, do professor, da instituição e a distância. Na segunda, focalizaremos os estudos sobre a auto-avaliação no contexto do ensino/ aprendizagem de língua estrangeira (doravante LE). Na terceira e última seção, apresentaremos as críticas feitas à auto-avaliação.

\section{Referencial teórico}

Esta seção está subdividida em três partes. Na primeira, discutiremos a definição e os objetivos gerais da auto-avaliação. As subseções seguintes referem-se às formas para empreendê-la e aos tipos de auto-avaliação mais utilizados no ensino. Para tal, tomamos como suporte teórico pesquisadores e estudiosos da Educação, bem como da área da Lingüística Aplicada. 


\section{Definição e Objetivo da Auto-avaliação}

A auto-avaliação é um processo pelo qual um indivíduo, além de avaliar uma produção, uma ação, ou uma conduta da qual ele é o autor, também avalia suas capacidades, seus gostos, seu desempenho, suas competências e habilidades. É um processo cognitivo complexo, pelo qual um indivíduo (aprendiz ou professor) faz um julgamento, com o objetivo de um melhor conhecimento pessoal, visando ao aperfeiçoamento de suas ações e ao seu desenvolvimento cognitivo.

Devido à sua característica reflexiva e ao seu caráter diagnóstico, a auto-avaliação não se processa apenas com relação aos aprendizes e professores, sendo desejável, também, que seja praticada pela instituição de ensino.

O objetivo da auto-avaliação, seja ela do aprendiz (presencial ou a distância), do professor ou da instituição de ensino, é analisar o processo de ensino/aprendizagem, para que as conclusões obtidas através das reflexões dos participantes revertam em benefícios tanto para o ensino quanto para a aprendizagem. Isso exige uma preparação dos professores, dos alunos e das pessoas que trabalham em uma instituição, para que as respostas sejam críticas, reflexivas e honestas, de forma que sejam gerados efeitos benéficos para o processo como um todo. Portanto, ao se conscientizarem de seu nível, de suas limitações e potencialidades, alunos, professores e instituições poderão ser capazes de oferecer uma melhor contribuição para o aprimoramento do processo ensino/aprendizagem.

Não encontramos, até o momento em que realizávamos a presente pesquisa, teses ou dissertações que tratassem do assunto. Por outro lado, observamos uma predominância de artigos e livros que enfocam a autoavaliação do aprendiz, o que nos leva a concluir que poucos são os professores e instituições de ensino que recorrem a essa prática. Portanto, neste trabalho, privilegiaremos a auto-avaliação do aluno.

\section{Auto-avaliação do Aluno, do Professor, da Instituição de Ensino e a Distância}

Embora existam outras formas de auto-avaliação, contemplaremos nesta subseção os seguintes aspectos, que podem ser melhor visualizados na FIG. 1, a seguir: 


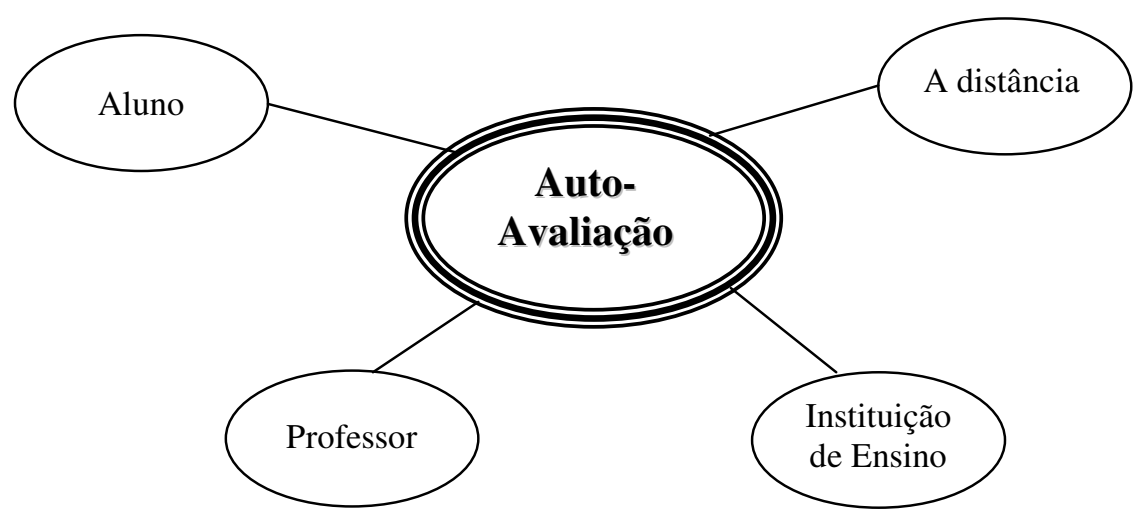

FIGURA 1 - Formas de Auto-Avaliação

\section{Auto-avaliação do Aluno}

A auto-avaliação é a forma que o aluno tem de interpretar seu próprio desempenho tanto em relação às suas atitudes e habilidades, como em relação ao seu desenvolvimento intelectual; ou seja, são procedimentos pelos quais os próprios aprendizes avaliam suas habilidades de linguagem e de conhecimento. Ela é fundamental no sentido de ajudar o professor a melhor conhecer seu aluno, sendo necessário, portanto, estar vinculada às intenções educativas explicitadas no projeto pedagógico da escola. Dessa forma, segundo Haydt (1997), a auto-avaliação incentiva o aprendiz a progredir, a realizar cada vez melhor as atividades subseqüentes e a identificar o que aprendeu e em que precisa melhorar.

Ao realizar esse trabalho de reflexão, o aluno estará analisando e pensando sobre o seu próprio processo de aprendizagem, desenvolvendo um conceito sobre si mesmo e reconhecendo que seu esforço pessoal o levará a um maior desenvolvimento; além disso, as informações obtidas através da auto-avaliação podem fornecer subsídios importantes aos aplicadores de provas e professores.

Lewkowicz e Moon (1985) advogam que, como a auto-avaliação é parte da experiência da aprendizagem, cabe ao professor estar preparado para ajudar os alunos a interpretar seus feedbacks. O sucesso da autoavaliação dependerá muito da forma com que o aluno percebe suas próprias necessidades e interpreta seus próprios feedbacks.

Segundo Nérici (1986), a auto-avaliação tem por finalidade levar o educando a refletir sobre os resultados atingidos durante o seu processo 
de aprendizagem. O autor sugere que, desde as primeiras séries, o aprendiz deve ser orientado a realizar um trabalho de auto-avaliação, pois, através dele, poderá dialogar com seus professores, conscientizando-se de seu papel na sociedade, de suas aptidões, possibilidades e aspirações, além de ser capaz de detectar suas próprias deficiências, refletir sobre seus deveres como estudante e motivar-se pelo processo de contínuo autoaperfeiçoamento.

Nérici (Op.cit.) observa que as perguntas inicialmente devem se referir a questões simples sobre o comportamento desejável relacionado ao educando, seus professores e colegas, subindo gradualmente até atingir as formas de comportamento mais complexas, relacionadas, também, às disciplinas ou áreas de conhecimentos, a fim de que ele possa ter um olhar mais crítico a respeito dos sucessos e insucessos escolares e do comportamento sócio-moral. Os primeiros anos do ensino fundamental servem como introdução à auto-avaliação, que deve ter início a partir do $2^{\circ}$ ou $3^{\circ}$ nível, nunca antes, sendo que as informações, de acordo com a sugestão do autor, podem ser registradas em fichas destinadas ao educando, para que, depois de devidamente explicadas, sejam por ele utilizadas em sua auto-avaliação. Através dessas fichas, os professores terão acesso a uma avaliação mais ampla do que aquela possibilitada pelas simples provas de verificação da aprendizagem.

Haydt (Op. cit.) sugere uma lista de verificação, elaborada a partir de um pequeno questionário, contendo perguntas ou itens sobre aspectos do comportamento do aluno, tais como: aproveitamento nos estudos, comportamento na escola, relacionamento com os colegas, participação nos trabalhos em grupo, condições de saúde, hábitos, sentimentos, atitudes, habilidades, interesses, preferências e aversões. Algumas listas são de uso do professor, para registro de observação. Outras devem ser respondidas pelos próprios educandos, oralmente ou por escrito, como guia para a autoavaliação. Os aspectos focalizados devem levar em conta o nível de desenvolvimento dos alunos e a sua formação escolar.

As listas de verificação, segundo Haydt (Op. cit.), podem ser planejadas pelo professor de acordo com o estágio de desenvolvimento e as necessidades dos alunos ou podem ser elaboradas cooperativamente por estes, através do levantamento de padrões de comportamento a serem seguidos e avaliados. Quando há participação dos alunos na elaboração das listas, eles se tornam mais responsáveis pela sua aprendizagem. Quando 
a lista for planejada pelo professor, o aluno deverá ter a liberdade de acrescentar itens de seu interesse, que julgue necessários para sua auto-avaliação, permitindo, assim, que constate por si mesmo quais são seus pontos fortes e fracos e considere o que the compete fazer para melhorar seu desempenho.

Para a autora, as fichas preenchidas pelo professor e pelo aluno poderão apresentar discrepâncias. Se isso ocorrer, maior atenção deve ser dirigida ao aluno. Deverão ser observados e localizados os fatores que influenciaram tais discrepâncias, que podem ocorrer se as duas partes observarem aspectos diferentes da avaliação: os aprendizes, por exemplo, podem estar se concentrando no produto final, isto é, na resposta, e os professores/observadores no processo usado para atingir tal resposta.

\section{Teste de Níveis de Conhecimentos ("Placement")}

Bailey (1998) cita, em seu artigo, uma pesquisa realizada no Canadá por LeBlanc e Painchaud, em 1985, com estudantes de francês e inglês, em que se constatou que o uso do questionário de auto-avaliação como um instrumento de teste de níveis de conhecimentos (placement) oferece várias vantagens sobre os testes padronizados, incluindo tempo reduzido de teste, eliminação dos problemas quanto à necessidade de supervisores e vigilância contra a 'cola', problemas com horário e locais para a prova. Também se concluiu que a auto-avaliação envolve bastante os aprendizes, uma vez que estes são responsáveis pela determinação de seus próprios níveis de conhecimento (placement).

A partir do momento em que o questionário de auto-avaliação é respondido com honestidade, os estudantes, segundo os autores citados por Bailey (Op. cit.), têm de refletir sobre suas habilidades lingüísticas, podendo ter uma visão mais clara de seu desempenho. Portanto, segundo a autora, os estudantes tornam-se mais conscientes de suas próprias necessidades e podem relacioná-las com o nível mais apropriado do programa, tornando-se menos ansiosos ao iniciarem seus estudos, porque sabem o que é esperado deles e o que eles podem esperar do professor.

Para evitar erros quanto ao seu próprio nível de conhecimento, Bailey (Op. cit.) sugere que os estudantes devem ser esclarecidos quanto ao que acontece em um determinado nível, evitando-se, assim, que classifiquemse abaixo ou acima de seu nível real. Além disso, pode-se pedir a um grupo de aprendizes para avaliar suas próprias habilidades e então comparar essas auto-avaliações com alguma avaliação externa. Esse é um exemplo do que 
é chamado validade relacionada a critério: uma medida é considerada válida até o ponto em que ela se correlaciona com outra medida mais amplamente aceita - o critério. Assim, por exemplo, uma estimativa do estudante dos aspectos da sua proficiência oral pode ser comparada com uma amostra dessa proficiência gravada, com dados de entrevista de proficiência oral, ou com escores de testes de lápis e papel.

Bailey (Op. cit.) cita também em seu artigo o estudo realizado por Peter Shaw. O referido autor desenvolveu sua pesquisa numa escola de línguas na cidade do México. Ao se matricular em um curso de línguas, o aluno começa com o processo de auto-avaliação, após observar o programa de ensino. O coordenador, enquanto interage com o aluno, faz uma estimativa do nível apropriado para ele e lhe mostra o material a ser utilizado, alguns tipos de exercícios, o livro de tarefas com as respostas e um exemplo de avaliações com as correções do professor. O aluno assiste a uma aula normal, conhece o professor e os alunos e depois discute com o coordenador qual é o nível adequado para ele.

Por outro lado, segundo Sheerin (1991, p. 152), a auto-avaliação, para um aprendiz verdadeiramente autônomo, não pode ser vista como uma comparação entre aquisição pessoal e normas definidas externamente nem como uma comparação com outros aprendizes; deve, antes, ser vista através de critérios definidos pelo aprendiz, de maneira individual, e é dependente de objetivos de aprendizagem pessoais.

\section{Auto-avaliação do Professor}

Seria fundamental que o professor realizasse um trabalho de autoavaliação quanto à sua ação como educador, visando a um aperfeiçoamento da sua prática pedagógica. Para Brighton (1965 apud PENNINGTON; YOUNG, 1989), a auto-avaliação docente é o objetivo final de qualquer programa de ensino; entretanto, esta requer professores capazes de compartilhar com seus colegas a responsabilidade pela melhoria do seu próprio desempenho.

Conforme Brighton (1965), a auto-avaliação deveria ser considerada como uma técnica essencial da educação, pois o professor que possui as habilidades necessárias para examinar e avaliar a sua própria competência e desempenho está em uma posição melhor para implementar mudanças. Convergindo com Brighton, Richards e Lockart (1994) afirmam que os professores estão mais capacitados para avaliar seu próprio ensino, sem 
que seja necessário recorrer a fontes externas, ou seja, através de coletas de dados sobre o seu ensino, utilizando algumas técnicas, como, por exemplo, observação, questionário e gravações audiovisuais, para que possa tentar responder a questionamentos tais como: "como e por que as coisas estão do jeito que estão"? e "que forma ou estrutura tem as minhas aulas"? Os autores afirmam que essa auto-avaliação precisa ser contínua e fazer parte da rotina de ensino do professor, para que este possa verificar se há lacunas entre o seu ensino e a aprendizagem dos alunos.

Pennington e Young (1989), baseando-se em Nunan (1988), apontam a auto-análise e auto-avaliação pelos professores como um meio de autodesenvolvimento. A auto-avaliação docente, quando aliada à pesquisa-ação em sala de aula, pode também trazer contribuições importantes para o desenvolvimento do currículo e para todo o processo de ensino/ aprendizagem.

Caroll (1981) fornece cinco técnicas, que, na sua concepção, são necessárias à implementação da auto-avaliação docente: formulários de auto-classificação (self-rating forms), auto-relatos, auto-material de estudo, observação do ensino de colegas e feedback através de gravações de áudio e vídeo sobre o próprio ensino. Essas técnicas permitirão ao professor examinar e questionar as suas atitudes, suas crenças, suas concepções de ensinar, de aprender e de avaliar; após essa auto-avaliação, ele poderá operacionalizar mudanças no seu ensino, se achar necessário.

Brighton (1965) e Nunan (1988), dentre outros, afirmam que as principais vantagens das técnicas de auto-avaliação são o potencial para a troca de experiências no ensino, o desenvolvimento do senso de responsabilidade, o profissionalismo e a focalização nos objetivos de ensino a longo prazo, tanto para o corpo docente quanto para o programa como um todo.

\section{Auto-Avaliação da Instituição de Ensino}

Com referência à auto-avaliação das escolas, Palma (1999) afirma que a aplicação desse tipo de avaliação deve ser rigorosa, para que proporcione uma sólida fundamentação a respeito das decisões a serem tomadas quanto à vida futura da escola e de todos os elementos da comunidade educativa. Para que os resultados se tornem aparentes, o autor sugere que um primeiro aspecto a ser contemplado é a criação de uma cultura de auto-avaliação da escola e a sua interiorização pela comunidade educativa, pois, sem ela, 
não há garantia de melhorias reais e efetivas na qualidade dos estabelecimentos de ensino. Assim, o processo deve envolver a participação ativa de todos: não só dos professores mas também dos alunos, do pessoal não-docente, dos pais e dos encarregados da educação, numa atitude de diálogo permanente, de procura de consensos, de negociação entre as diferentes perspectivas existentes e de interpretação crítica e aberta dos resultados obtidos. Segundo Palma (Op. cit.), a coleta de informações (tanto de natureza qualitativa como estatística), que deverá estar na base desse processo, deve ser criteriosa, com uma noção clara dos objetivos e das dimensões da avaliação que serão privilegiadas.

\section{Auto-Avaliação a Distância}

Percebe-se, em alguns artigos pesquisados na Internet, que a avaliação, tanto no ensino presencial quanto no ensino a distância, é parte fundamental, uma vez que através dela o aluno pode ter maior consciência de seu aprendizado e, nesse contexto, ter uma melhor orientação dos caminhos a seguir. O mecanismo de "auto-avaliação" é incluído na preparação do curso a distância, porém, pouca ou quase nenhuma informação é fornecida sobre como ocorre tal procedimento. Dos textos analisados, podemos destacar os seguintes trechos que mencionam a autoavaliação neste contexto específico.

Em seu artigo sobre educação a distância, Neder (1996) afirma que o ambiente de aprendizagem precisa disponibilizar uma série de itens, tais como roteiros para auto-avaliação e avaliação da aprendizagem. Neder (Op. cit.), ao discorrer sobre avaliação, menciona que todo fascículo do estudo a distância deve apresentar possibilidades de auto-avaliação e, além disso, de atividades que liguem a teoria à prática.

Vários estudiosos sobre avaliação consideram que, dentro de um curso a distância, há vários momentos em que a avaliação ocorre. Num primeiro momento, o aluno responde a perguntas de auto-avaliação (perguntas intercaladas com o texto, ou no final de uma unidade, que servem como referencial para que o próprio aluno perceba sua compreensão do conteúdo). Posteriormente, são preenchidos cadernos de avaliação com questões que os estudantes respondem e enviam ao professor. Além desses dois tipos, o aluno ainda faz o que é denominado de avaliação presencial (provas nas quais demonstra até que ponto o estudo feito a distância foi fruto do seu esforço pessoal como estudante). Observamos que, embora a 
auto-avaliação seja considerada fundamental no processo a distância, é colocada apenas como mera referência nos artigos pesquisados.

\section{Auto-avaliação no Ensino/Aprendizagem de Língua Estrangeira}

As questões que envolvem a auto-avaliação aparecem, com uma certa regularidade, em discussões tanto na Educação em geral como na Lingüística Aplicada. Enquanto essas discussões giram em torno da credibilidade e da validade dessa avaliação, pouca atenção tem sido dada ao real valor da auto-avaliação como uma alternativa viável para os exames de proficiência e de rendimentos, particularmente na avaliação de LE. Os escassos estudos na área de ensino/aprendizagem de LE parecem ser subprodutos de estudos mais complexos sobre validade de construto - as conhecidas abordagens usadas por Bachman e Palmer (1982).

Para Folk (1981 apud BLANCHE; MERINO, 1989), a auto-avaliação deveria ser analisada como qualquer outro instrumento de avaliação e, portanto, considerando os critérios de confiabilidade e validade. No entanto, segundo Bachman e Palmer (1982), as pesquisas conduzidas, até agora, focalizam a comparação da auto-avaliação com outras provas, e raramente em termos de construtos de proficiência da linguagem.

Ross (Op. cit.) realizou uma análise empírica da validade de vários instrumentos de auto-avaliação. Duzentos e trinta e seis aprendizes de inglês como LE preencheram um instrumento de auto-avaliação de suas habilidades e, ao mesmo tempo, o grupo foi avaliado pelos professores. As análises contrastivas demonstraram discrepâncias entre a auto-avaliação e a avaliação feita pelo professor, dependendo da experiência de linguagem dos alunos na habilidade auto-avaliada. Um exame mais criterioso do processo de autoavaliação sugeriu ao autor que o grau de experiência trazido para o contexto avaliado pelo aprendiz influencia a "precisão"² da auto-avaliação.

A pesquisa também demonstra que cada habilidade (leitura, escrita, compreensão oral e produção oral) deve ser avaliada de maneira independente, pois facilita a auto-análise do aprendiz. Os aprendizes de LE necessitam saber quais são suas habilidades mais desenvolvidas, como estão progredindo e o que eles são capazes de fazer ou não com as adquiridas. Do ponto de

${ }^{2} \mathrm{O}$ termo precisão está sendo usado para se referir à nota mais próxima da avaliação realizada pelo professor. 
vista educacional, conhecer e avaliar seu próprio desempenho é muito importante, uma vez que os alunos não terão de depender inteiramente da opinião de seus professores e, ao mesmo tempo, serão capazes de levar aos professores suas necessidades individuais de aprendizagem. Ross (1998) considera e analisa os resultados obtidos em cada uma das habilidades específicas: leitura, compreensão oral, produção oral e escrita.

\section{Auto-avaliação da Leitura}

Segundo Ross (1998), o fato de a leitura ser provavelmente a primeira habilidade desenvolvida no contexto de aprendizagem/ensino de LE, poderá trazer maior confiança ao aluno, tornando a auto-avaliação nessa habilidade mais válida do que nas outras. Para o autor, em muitos contextos de LE, a exposição à palavra escrita precede às inúmeras oportunidades de práticas bem-sucedidas da produção e compreensão oral, podendo influenciar na precisão do aluno ao se auto-avaliar.

\section{Auto-avaliação da Compreensão Oral}

De acordo com Ross (Op. cit.), há uma grande variação quanto à precisão dos alunos ao se auto-avaliarem nessa habilidade. Essa variação pode ser causada pelo fato de que as experiências dos aprendizes com a compreensão oral na LE são menos intensas do que na leitura e também pela possibilidade de os ouvintes em contexto de LE avaliarem suas habilidades em termos absolutos e não relativos. Por exemplo, os aprendizes pertencentes a um grupo mais avançado poderão avaliar sua habilidade de compreensão oral em relação aos alunos menos avançados.

\section{Auto-avaliação da Produção Oral e da Escrita}

As pesquisas da auto-avaliação em LE demonstraram um grande número de correlações de auto-avaliação com a produção oral, sugerindo que há uma expectativa de relação entre a experiência do aluno em determinada habilidade e a sua respectiva auto-avaliação, conforme afirma Ross (Op. cit.). No entanto, as análises de auto-avaliações de produções orais demonstram que os aprendizes são, na verdade, menos experientes (competentes) para avaliarem a própria produção oral.

As pesquisas da auto-avaliação em LE demonstraram um grande número de correlações de auto-avaliação com a produção oral, sugerindo que há 
uma expectativa de relação entre a experiência do aluno em determinada habilidade e a sua respectiva auto-avaliação, conforme afirma Ross (Op. cit.).

Para o autor, é muito importante considerar que os critérios de avaliação da produção oral sejam suscetíveis à variação e que essa habilidade é, geralmente, avaliada holisticamente através de entrevistas que possuem o controle formal da gramática como viés. Ross aponta que muitas vezes os falantes da LE poderão avaliar suas próprias habilidades, tendo como referência suas intenções comunicativas mais do que o efeito verdadeiro de seus esforços para transmitirem uma mensagem ao seu interlocutor.

Ross (Op. cit.) destaca que é importante lembrar que a leitura e a compreensão oral são habilidades receptivas que não requerem do aprendiz planejamento com antecedência nem execução de estratégias específicas de produção. Se a consciência metalingüística e metacognitiva são instrumentais na comunicação, devemos esperar que os aprendizes sejam mais conscientes nas habilidades produtivas (oral e escrita), tornando a autoavaliação dessas habilidades mais confiável.

\section{Aspectos Gerais da Auto-avaliação em LE}

Segundo Ross (1998), o mais completo estudo na área de autoavaliação em LE é de Blanche e Merino (1989), pois apresenta amostras, metodologia e variáveis de critérios de diversas pesquisas de proficiência que utilizaram a auto-avaliação. No entanto, Ross considera esse estudo limitado ao terreno da subjetividade.

Blanche e Merino (1989) realizaram essa pesquisa sobre a autoavaliação através de vários relatórios de estudos teóricos e práticos da autoavaliação de alunos de Ensino Médio (" $h i g h$ school") e de universidades, a maioria de inglês como LE. Diversos tipos de instrumentos de avaliação foram utilizados, alguns com objetivos gerais de pesquisa e outros como parte da avaliação contínua em situações comuns de aprendizagem.

Esses estudos incluíram comparações entre auto-avaliação e medidas mais objetivas de proficiência. Os itens da auto-avaliação que pareceram conter respostas mais precisas foram os relacionados às situações lingüísticas concretas.

A necessidade de se praticar a autonomia e a auto-avaliação foi amplamente enfatizada. No entanto, Blanche e Merino (1989) concluem que a mudança de visão e conseqüentemente da prática do professor são importantes requisitos para um desenvolvimento efetivo de um ensino centrado no aprendiz. 
Em nenhum dos estudos revisados, a idade ou o nível de desenvolvimento cognitivo dos alunos que se auto-avaliaram foram levados em consideração. Contudo, as autoras sugerem que pesquisas sejam feitas na tentativa de identificar se a auto-avaliação é mais fácil para os jovens do que para os mais velhos. Isso ajudaria a entender melhor e a desenvolver uma teoria sobre a maneira como a auto-avaliação funciona com todos os alunos.

Para as autoras, os estudos sobre auto-avaliação encontram suporte na Teoria/Modelo do Monitor de Krashen, pois a consideram como sendo a única dentre as teorias de LE que trata diretamente da auto-avaliação. O modelo de Krashen (Op. cit.) contempla discrepâncias de desempenho das habilidades oral e escrita de determinados alunos e o fato de alguns possuírem competência gramatical, enquanto não parece tornar outros capazes de se comunicar muito bem. O Modelo admite e prevê que o desempenho dos alunos terá variação, dependendo do grau de utilização do Monitor.

Até certo ponto, a Teoria do Monitor de Krashen (Op. cit.) parece considerar as diferenças de valores da auto-avaliação observados em vários estudos: enquanto o Monitor tem apenas a função de produzir, os aprendizes geralmente se auto-corrigem, usando a aquisição na língua materna e na LE (BLANCHE; MERINO, 1989, p. 326).

Blanche e Merino (1989) afirmam que o nível de desenvolvimento cognitivo do aprendiz depende do grau de instrução formal que ele possui. A expectativa das autoras era de que a quanto mais prática e insumo o aprendiz estivesse exposto, maior seria a capacidade de monitoramento. ${ }^{3} \mathrm{No}$ entanto, em um dos seus experimentos, nem o conhecimento anterior nem a exposição à LE parecem ter tido um efeito significativo nas discrepâncias entre as notas da auto-avaliação e as de outros instrumentos, confirmando assim os estudos de Krashen (1982) em relação ao conhecimento consciente das regras de linguagem e a não-garantia de que a língua será usada.

As autoras reiteram as conclusões de Krashen (Op.cit.) a respeito da função do monitoramento apenas fazer sentido depois que as estratégias

\footnotetext{
${ }^{3}$ Essa capacidade de monitoramento leva em consideração uma das cinco hipóteses proposta por Krashen (1982), que é a hipótese do monitor. Para o referido autor, a aquisição e a aprendizagem são processos bem específicos. Normalmente, a aquisição faz com que o indivíduo se comunique de forma espontânea e é responsável por sua fluência. Por outro lado, a aprendizagem só tem uma função, ou seja, a de monitor ou editor (Cf. KRASHEN, 1982).
} 
de comunicação estiverem, de alguma forma, desenvolvidas e que o processo estiver bem estabelecido. A natureza e o foco da tarefa de completar com o tempo verbal correto, por exemplo, poderá exigir maior monitoramento do aprendiz do que tarefas que focalizam a comunicação (KRASHEN, 1982). Conseqüentemente, o Monitor deveria ser mais eficiente na escrita e em exercícios de produção em que o aprendiz possa se preparar anteriormente para tal tarefa.

Em metade dos estudos examinados pelas autoras (HEIDT, 1979; HEINDLER, 1980; FOLK, 1981; LOW, 1981, 1982; Von ELEK, 1981, 1982; FERRIS, 1982), ${ }^{4}$ os pesquisadores concluíram que as práticas de autoavaliação pareceram ter aumentado a motivação dos alunos. Outros pesquisadores concluíram que os aprendizes mais proficientes tendem a subestimar suas habilidades lingüísticas (FERGUSON, 1978; ACHARA, 1980; HEIDLER, 1980; EVERS, 1981; BOURNEMOUTH EUROCENTRE, 1982). AO contrário, os casos de supervalorização envolveram alunos mais fracos do que fortes (FERGUSON, 1978; HEINDLER, 1980; BLANCHE, 1986). ${ }^{5}$

As baixas notas de auto-avaliação foram relacionadas às duas áreas de aprendizagem de língua: gramática (PALMER; BACHMAN, 1982; Von ELEK, 1981, 1982; ANDERSON, 1982; BLANCHE, 1986) e pronúncia (RAASCH, 1979, 1980).

Com base nas pesquisas, conclui-se que a maioria dos aprendizes tende a se auto-avaliar mais facilmente nas suas habilidades comunicativas.

\section{Críticas à Auto-Avaliação}

A auto-avaliação não é um processo neutro e, por envolver participantes das mais diversas culturas, contextos sociais discrepantes, diferentes vertentes acadêmicas e variados contextos de ensino/ aprendizagem, sofre influências de infinitas variáveis que podem se transformar em restrições no momento em que a auto-avaliação é aplicada. Essas variáveis, que podem afetar a confiabilidade do instrumento, estão sujeitas à subjetividade e a limitações tanto de quem elabora quanto de quem responde às questões. As idiossincrasias, o excesso de autoconfiança, a subestimação de capacidades, a honestidade e a boa vontade de quem

\footnotetext{
${ }^{4}$ Todas essas referências se encontram em Blanche e Merino (1989).

${ }^{5}$ Todas essas referências foram elucidadas e discutidas em Blanche e Merino (1989).
} 
responde, a conscientização e a capacidade de refletir são também questões que devem ser consideradas.

Régnier (1999) afirma que, por ser uma prática subjetiva, a autoavaliação pode gerar situações de desconfiança, podendo ocorrer, por um lado, a subestimação de uma competência e, por outro, a superestimação dessa competência, devido ao despreparo para a realização dessa tarefa.

McLaughlin e Rossman (1983) apresentam um argumento semelhante, ao descobrir que bons alunos geralmente se subestimam ou se avaliam da mesma maneira que o professor, enquanto os alunos que alcançaram um nível intermediário de proficiência lingüística, além do qual eles não conseguem, progredir (alunos plateaued), pelo menos temporariamente, se superestimam, e os realmente fracos não parecem discriminar entre uma habilidade e outra, descrevendo-se simplesmente como fracos. Isso acontece pelo fato de que os bons alunos estão aprendendo e estão começando a ter consciência de tudo o que ainda não sabem. Os aprendizes "plateaued", por outro lado, apresentam essa característica porque não vêem necessidade de melhorar e tendem a se superestimar.

Segundo Blanche e Merino (1989), com relação ao ensino/aprendizagem de LE, os alunos, muitas vezes, não possuem discernimento suficiente para se comparar com falantes nativos. Para as autoras, a questão maior recai sobre a confiabilidade do julgamento desses alunos, que poderá ser prejudicada pelos fatores de afetividade e traços de personalidade, que desempenham importantes papéis no complexo processo de aprendizagem de LE.

Ainda segundo Blanche e Merino (Op. cit.), em se tratando de autoavaliação da leitura, pode ocorrer que os alunos menos proficientes, especialmente aqueles pertencentes a um contexto de LE, superestimem essa habilidade, enquanto os mais proficientes a subestimem.

Alguns investigadores concluíram que a auto-avaliação pode ser afetada por erros subjetivos, tais como experiências anteriores malsucedidas na aprendizagem de uma LE, aspiração profissional, expectativas dos colegas e dos pais e falta de treinamento para estudar sozinho. A questão cultural relacionada à auto-avaliação foi outro fator agravante. Constatouse que a maioria dos professores e alunos estão fortemente familiarizados com seus respectivos papéis tradicionais de elaborar/aplicar e fazer provas.

Reiteramos que, apesar das restrições, as vantagens quanto à utilização da auto-avaliação como mecanismo de desenvolvimento do ensino/ aprendizagem em muito superam essas limitações. Estamos conscientes 
de que toda a complexidade desse processo poderá ser melhor compreendida não apenas com a participação, boa vontade e colaboração de todos, até mesmo das instituições de ensino. A utilização da autoavaliação poderá atingir seus benefícios potenciais através de professores que possuam uma compreensão profunda e reflexiva de sua prática, sejam conscientes da abordagem, concepções e crenças que norteiam seu ensino e, principalmente, que saibam orientar seus alunos, tornando-os mais envolvidos com a própria aprendizagem e avaliação.

\section{Considerações Finais}

O emprego da auto-avaliação, apesar das críticas já apontadas anteriormente, oferece muitas vantagens, pois, a partir do momento em que é realizada com senso crítico, de modo reflexivo, responsável e autônomo, as vantagens são inúmeras.

A auto-avaliação, empregada junto a outros instrumentos de avaliação, pode fornecer uma visão mais precisa para professores e alunos sobre o seu nível de conhecimento ou desempenho, diminuindo a possibilidade de distorções, afastando o conceito de avaliação como instrumento de medida de produto e colaborando para torná-la processual.

Embora, em nosso país, a auto-avaliação da instituição de ensino não pareça ser uma prática costumeira, ela também pode representar um potencial para o desenvolvimento do ensino. A partir da reflexão de todos, não só daqueles diretamente envolvidos mas também da comunidade como um todo, ao emitir opiniões, e refletindo acerca do desempenho e funcionamento da instituição, através do diálogo e consenso entre as diferentes correntes político-ideológicas e educacionais presentes, as interpretações dos resultados obtidos poderão reverter em benefícios para a instituição.

Assim, ao partilhar as decisões dentro da instituição com todos os interessados, a auto-avaliação deixa de lado o caráter corporativista, em que uma minoria de 'especialistas' toma decisões de interesse coletivo, podendo causar conflitos pela divergência de opiniões. Portanto, quando há, na escola, uma política de auto-avaliação compartilhada, as mudanças podem ocorrer, após um consenso, de maneira que essas transformações adquiram um novo sentido.

Quando a auto-avaliação é feita através de critérios bem estabelecidos, eliminam-se certas crenças que permeiam este instrumento de avaliação: por 
um lado, há os que acreditam na importância e na utilidade desse processo e, por outro, há os que afirmam ser a auto-avaliação um instrumento impossível de ser aplicado. A primeira corrente advoga que o aluno deve aprender a identificar o seu potencial e suas fraquezas, enquanto a segunda considera que o aluno é muito jovem para conseguir identificá-los.

Assim, a despeito das restrições, podemos considerar que autoavaliação, seguramente, poderá trazer grandes benefícios para o ensino/ aprendizagem. Quando bem utilizada, poderá produzir um efeito retroativo benéfico, contribuindo para que a instituição de ensino, alunos e professores tenham uma visão mais clara de suas limitações, potencialidades, erros e acertos, visando à solução de problemas e melhorias no ensino.

As pesquisas mostram que a nossa cultura de avaliar ${ }^{6}$ ainda apresenta marcas de antigos paradigmas, que a auto-avaliação ainda não é amplamente utilizada em nossas escolas, e que, em alguns casos, o seu objetivo não parece estar diretamente relacionado com o ensino/ aprendizagem, possivelmente pela ausência de subsídios teóricos por parte de alguns professores, alunos e instituições de ensino. Portanto, cabe a nós, pesquisadores e professores, cuja oportunidade de discutir essas questões nos foi disponibilizada através de uma disciplina do curso de Pós-Graduação Stricto Sensu (Mestrado e Doutorado) em Lingüística Aplicada, ${ }^{7}$ divulgar e implementar novos conceitos alicerçados em paradigmas inovadores, mas sempre levando em conta que, antes de tudo, é essencial a preparação através de um planejamento bem estruturado, além da explicitação dos objetivos, e levando-se em conta as necessidades dos envolvidos no processo.

Concluindo, consideramos fundamental ressaltar que a auto-avaliação poderá constituir uma forma de trazer o olhar do aluno juntamente ao do professor, de envolver o aprendiz em seu processo avaliativo, sem, contudo, substituir a avaliação do professor e, assim, passar de um sistema autoritário,

\footnotetext{
${ }^{6}$ Neste trabalho, o termo "cultura de avaliar" é adotado de Scaramucci (1997, p. 77), para referir às "crenças, pressupostos teóricos, atitudes, mitos - construídos ao longo dos anos, a partir de nossas experiências de aprender e ensinar, muitas vezes superadas e sem reflexão - e que acabam por determinar, na maioria das vezes, de forma insconsciente, os rumos de nossa prática".

${ }^{7}$ A disciplina que fazemos menção é Avaliação em Língua Estrangeira/Segunda Língua, ministrada pela Professora Dra. Matilde Virginia Ricardi Scaramucci, no Instituto de Estudos da Linguagem (IEL) da Universidade Estadual de Campinas (UNICAMP), no segundo semestre letivo de 2003
} 
que necessita de controles externos, centralizado no professor, para um outro que depende também da maturidade e conscientização do aluno em assumir seu papel de aprender. "Esta mudança tem de ser gradual, responsável, para não vir a banalizar a tarefa de ensinar e avaliar. Tem de ser um processo trabalhado pelo professor e pelo aluno, cada um cumprindo sua parte no contrato" (SCARAMUCCI, 1998/1999, p. 120).

\section{Referências Bibliográficas}

BACHMAN, L. F.; PALMER, A. S. The construct validation of some components of communicative proficiency. Tesol Quarterly, v. 16, p. 449-65, 1982.

BAILEY, K. Self Assessment in Language Learning. In: FREEMAN, D. (Ed.). Learning about language assessment: dilemmas, decisions and directions. New York: Heinle \& Heinle, 1998. Teacher Source.

BLANCHE, P.; MERINO, B. Self-assessment of Foreign-Language Skills: Implications for teachers and researchers. Language Learning, v. 39, n. 3, p. 75-93, 1989.

BRIGHTON, S. Increasing your accuracy in teacher evaluation. Englewood Cliffs, NJ: Prentice Hall, 1965.

CARROLL, J. G. Faculty self-evaluation In: MILLMAN, J. (Ed.). Handbook of teacher evaluation. Beverly Hills, CA.: Sage, 1981. p. 180-200.

CRABBE, D. Fostering autonomy from within the classroom: the teacher's responsibility. System, Great Britain: Pergamon Press, v. 21, n. 4, p. 441-452, 1993.

DICKINSON, L. Self-instruction in language learning. Great Britain: Cambridge University Press, 1987.

HAYDT, R. C. C. Avaliação do Processo Ensino-Aprendizagem. 5. ed. São Paulo: Ática, 1997.

HILL, B. Self-managed learning. Language Teaching. Cambridge: CUP, n. 27, p. 213-223, 1994.

KRASHEN, S. D. Principles of Second Language Acquisition. New York: Prentice-Hall, 1982.

LEWCOWICZ, J. A; MOON, J. Evaluation: A way of involving the learner. In: ALDERSON, J. C. (Ed.). Evaluation. Lancaster. Papers in English Language Education, Oxford: Pergamon, v. 6, 1985. 
LUCKESI, C. C. Verificação ou avaliação: o que pratica a escola? In: LUCKESI, C. C. Avaliação da aprendizagem escolar. São Paulo: Cortez, 1996. p. 85-101.

LUCKESI, C. C. Avaliação do aluno: a favor ou contra a democratização do ensino? In: LUCKESI, C. C. Avaliação da aprendizagem escolar. São Paulo: Cortez, 1996. p. 60-84.

LUCKESI, C. C. Avaliação educacional escolar: para além do autoritarismo. In: LUCKESI, C. C. Avaliação da aprendizagem escolar. São Paulo: Cortez, 1996. p. $27-47$.

MACEDO, H. Avaliação Escolar. Disponível em: <http://www.projetoeducar. com.br/avalia/relato1.htm>. Acesso em: 1998.

MCLAUGHLIN, B.; ROSSMAN, T; MCLEOD, B. Second Language Learning: An Information Processing Perspective. Language Learning, v. 33, p. 135157, 1983.

MOITA LOPES, L. P. Oficina de lingüística aplicada: a natureza social e educacional dos processos de ensino/aprendizagem de línguas. Campinas: Mercado de Letras, 1996.

NEDER, M. L. Avaliação na educação a distância - significações para definição de percursos. In: PRETI, O. (Org.). Educação a Distância: inícios e indícios de um percurso. Cuiabá: NEAD/IE - UFMT, 1996.

NÉRICI, G. I. Didática: uma introdução. São Paulo: Atlas, 1986.

NUNAN, D. Understanding language classrooms. Hemel Hempstead: Prentice Hall International, 1988.

OSKARSSON, M. Self-assessment of foreign language skills: a survey of research and development work. Strasbourg: Council of Europe, 1984.

PALMA, B. Por uma cultura de auto-avaliação das escolas. Disponível em: $<$ http://www.iie.min-edu.pt/edicoes/noe/noe50/dossier4.htm>. Acesso em: 1999.

PENNINGTON, M. C.; YOUNG, A. L. Approaches for faculty evaluation for ESL, Tesol Quartely, v.23, n. 4, p. 615-646, dez. 1989.

RÉGNIER, J. C. A auto-avaliação na prática pedagógica. Revista da Rede de Avaliação Institucional da Educação Superior, Campinas, v. 4, n. 4, p. 47-52, dez.1999.

RICHARDS, J.; LOCKHART, C. Reflective teaching in second language classrooms, Cambridge: Cambridge University Press, 1994. 
ROSS, S. Self-assessment in second language testing: a meta-analysis of experiential actors, Language Testing, v. 15, n. 1, p. 1-20, 1998.

SCARAMUCCI, M. V. R. Avaliação de rendimento no ensino de português língua estrangeira. In: ALMEIDA FILHO, J. C. P. (Org.). Parâmetros atuais para o ensino de português lingua estrangeira. Campinas: Pontes, 1997. p. $75-88$.

SCARAMUCCI, M. V. R. Avaliação: mecanismo propulsor de mudanças no ensino/aprendizagem de língua estrangeira, Revista Contexturas, APLIESP, p. $75-81,1998 / 1999$.

SHEERIN, S. Self-access: state of the art article. Language Teaching, Cambridge University Press, v. 24, n. 1, p. 143-157, 1991.

SHOHAMY, E. Language Testing: matching assessment procedures with language knowledge. In: BIRENBAUM, M.; DOCHY, F. (Ed.). Alternatives in Assessment of Achievement, Learning Processes and Prior Knowledge. Boston, MA: Kluer Academic Publishers, 1995. P. 142-160. 


\section{Anexos}

\section{ANEXO 1 - Auto-Avaliação do Professor ${ }^{8}$}

Docente:

Curso:

Disciplina(s)

Avalie seu próprio desempenho no $1^{\circ}$ Semestre de 2001, mediante a atribuição de uma nota de 1 a 10, assinalando com x na coluna apropriada, de acordo com a escala abaixo:

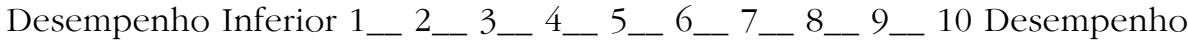
Superior

Deixe em branco os itens que você não tiver condições de avaliar

\begin{tabular}{|c|c|c|c|c|c|c|c|c|c|c|c|c|}
\hline & & 1 & 2 & 3 & 4 & 5 & 6 & 7 & 8 & 9 & & 10 \\
\hline 01 & $\begin{array}{l}\text { Conheço profundamente o conteúdo que } \\
\text { leciono e matenho-me atualizado na minha } \\
\text { disciplina e nas disciplinas correlatas. }\end{array}$ & & & & & & & & & & & \\
\hline 02 & $\begin{array}{l}\text { Dou aula em linguagem clara, objetiva e } \\
\text { adequada ao nível da turma. }\end{array}$ & & & & & & & & & & & \\
\hline 03 & $\begin{array}{l}\text { Estimulo a participação do aluno, dando-lhe } \\
\text { oportunidade para questionar. }\end{array}$ & & & & & & & & & & & \\
\hline 04 & $\begin{array}{l}\text { Promovo ligação entre teoria e prática, } \\
\text { exemplifi-cando e/ou introduzindo atividades } \\
\text { práticas, quando possível. }\end{array}$ & & & & & & & & & & & \\
\hline 05 & $\begin{array}{l}\text { Uso estratégias de ensino variadas e material de } \\
\text { apoio (textos, recursos audiovisuais etc.) } \\
\text { apropriados. }\end{array}$ & & & & & & & & & & & \\
\hline 06 & $\begin{array}{l}\text { Procuro despertar no aluno o interesse para a } \\
\text { disciplina. }\end{array}$ & & & & & & & & & & & \\
\hline 07 & $\begin{array}{l}\text { Demonstro qual a importância da disciplina } \\
\text { para o futuro profissional e como ela poderá ser } \\
\text { utilizada na vida prática. }\end{array}$ & & & & & & & & & & & \\
\hline 08 & $\begin{array}{l}\text { Apresento meu plano de disciplina (conteúdo } \\
\text { programático, objetivos, bibliografia, avaliação) } \\
\text { no início do ano letivo. }\end{array}$ & & & & & & & & & & & \\
\hline 09 & $\begin{array}{l}\text { Cumpro meu plano de ensino, com } \\
\text { flexibilidade. }\end{array}$ & & & & & & & & & & & \\
\hline 10 & $\begin{array}{l}\text { Solicito e acato sugestões dos alunos no sentido } \\
\text { de melhorar o aproveitamento da disciplina, } \\
\text { aceitando que com o aluno também aprendo. }\end{array}$ & & & & & & & & & & & \\
\hline
\end{tabular}

${ }^{8}$ Este instrumento foi aplicado numa Instituição de Ensino Superior localizada numa cidade de porte médio do sudeste brasileiro. 
11 Preparo minhas atividades de aula.

12 Integro o conteúdo da disciplina com os conheci-mentos de outras disciplinas.

13 Uso critérios de avaliação justos e conhecidos do aluno, compatíveis com os conteúdos ministrados.

14 Realizo avaliações compatíveis com os conteúdos abordados.

15 Comunico e discuto posteriormente os resultados das avaliações realizadas na disciplina, procurando sanar todas as dúvidas da turma.

16 Aceito as dificuldades e limitações do aluno, fazendo críticas construtivas sem humilhá-lo.

17 Trato o aluno com atenção e respeito, contornando problemas sem demonstrar irritação.

18 Mantenho disciplina adequada para uma aprendi-zagem eficiente.

19 Repito explicações, quando necessário, sem mostrar aborrecimento.

20 Crio condições para uma visão crítica da realidade e construo com os alunos uma postura ética quanto à prática da futura profissão.

21 Gosto de ensinar e considero importante meu trabalho.

22 Sou pontual quanto ao horário de aulas e demais compromissos.

23 Aproveito adequadamente o tempo de aula disponível.

24 Preocupo-me em relacionar os conteúdos trabalhados em aula com o contexto social.

25 Estimulo o desenvolvimento do pensamento crítico/reflexivo do aluno.

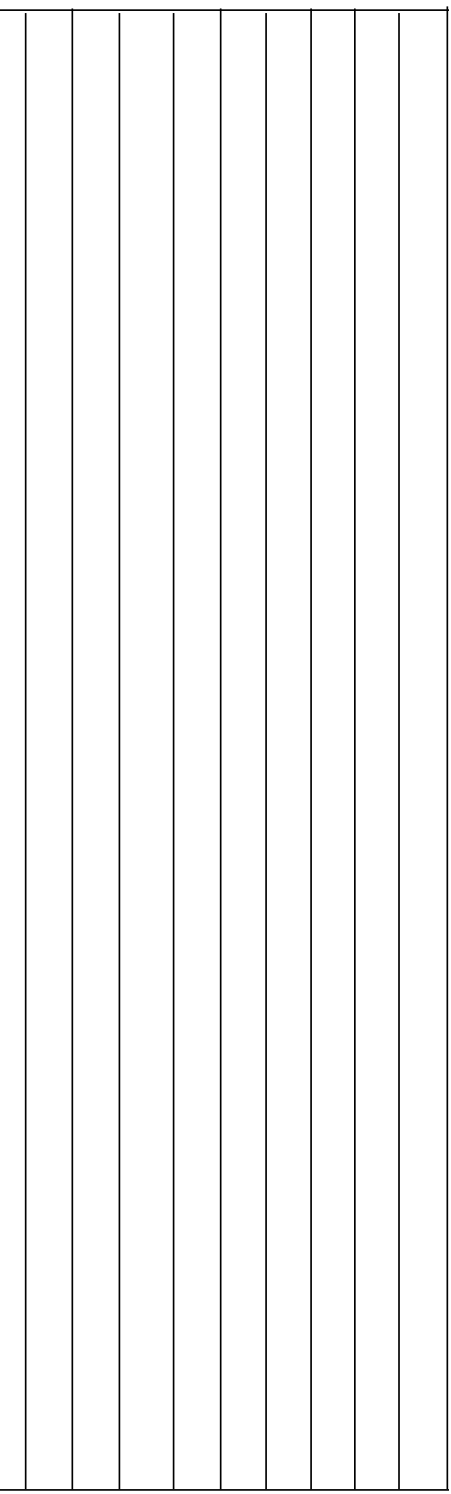




\section{ANEXO 2 - Auto-Avaliação de Desempenho do Professor na Perspectiva dos Alunos ${ }^{9}$}

Atribua notas de 1 a 10 a cada item para avaliar o desempenho de seus professores durante o $1^{\circ}$ Semestre de 2001, de acordo com a escala abaixo:

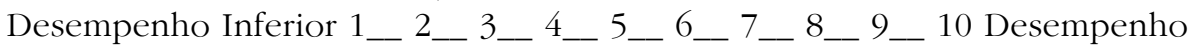
Superior

Deixe em branco os itens que você não tiver condições de avaliar

\begin{tabular}{|c|c|c|c|c|c|c|c|c|c|c|c|}
\hline & & 1 & 2 & 3 & 4 & 5 & 6 & 7 & 8 & 9 & 10 \\
\hline 01 & $\begin{array}{l}\text { Demonstra conhecer profundamente o } \\
\text { conteúdo que leciona e mantém-se atualizado } \\
\text { na sua disciplina e nas disciplinas correlatas. }\end{array}$ & & & & & & & & & & \\
\hline 02 & $\begin{array}{l}\text { Dá aula em linguagem clara, objetiva e } \\
\text { adequada ao nível da turma. }\end{array}$ & & & & & & & & & & \\
\hline 03 & $\begin{array}{l}\text { Estimula a participação do aluno, dando-lhe } \\
\text { oportunidade para questionar. }\end{array}$ & & & & & & & & & & \\
\hline 04 & $\begin{array}{l}\text { Promove ligação entre teoria e prática, exempli- } \\
\text { ficando e/ou introduzindo atividades práticas, } \\
\text { quando possível. }\end{array}$ & & & & & & & & & & \\
\hline 05 & $\begin{array}{l}\text { Usa estratégias de ensino variadas e material de } \\
\text { apoio (textos, recursos audiovisuais etc.) } \\
\text { apropriados. }\end{array}$ & & & & & & & & & & \\
\hline 06 & $\begin{array}{l}\text { Procura despertar no aluno o interesse para a } \\
\text { disciplina. }\end{array}$ & & & & & & & & & & \\
\hline 07 & $\begin{array}{l}\text { Demonstra qual a importância da disciplina } \\
\text { para o futuro profissional e como ela poderá ser } \\
\text { utilizada na vida prática. }\end{array}$ & & & & & & & & & & \\
\hline 08 & $\begin{array}{l}\text { Apresenta seu plano de disciplina (conteúdo } \\
\text { programático, objetivos, bibliografia, avaliação) } \\
\text { no início do ano letivo. }\end{array}$ & & & & & & & & & & \\
\hline 09 & Cumpre seu plano de ensino, com flexibilidade. & & & & & & & & & & \\
\hline 10 & $\begin{array}{l}\text { Solicita e acata sugestões dos alunos no sentido } \\
\text { de melhorar o aproveitamento da disciplina, } \\
\text { aceitando que com o aluno também aprende. }\end{array}$ & & & & & & & & & & \\
\hline 11 & Demonstra preparar suas atividades de aula. & & & & & & & & & & \\
\hline 12 & $\begin{array}{l}\text { Integra o conteúdo da disciplina com os } \\
\text { conheci-mentos de outras disciplinas. }\end{array}$ & & & & & & & & & & \\
\hline 13 & $\begin{array}{l}\text { Usa critérios de avaliação justos e conhecidos } \\
\text { do aluno, compatíveis com os conteúdos } \\
\text { ministrados. }\end{array}$ & & & & & & & & & & \\
\hline
\end{tabular}

${ }^{9}$ Este instrumento foi aplicado numa Instituição de Ensino Superior localizada numa cidade de porte médio do sudeste brasileiro. 
14 Realiza avaliações compatíveis com os conteúdos abordados.

15 Comunica e discute posteriormente os resultados das avaliações realizadas na disciplina, procurando sanar todas as dúvidas da turma.

16 Aceita as dificuldades e limitações do aluno, fazendo críticas construtivas sem humilhá-lo.

17 Trata o aluno com atenção e respeito, contornando problemas sem demonstrar irritação.

18 Mantém disciplina adequada para uma aprendizagem eficiente.

19 Repete explicações, quando necessário, sem mostrar aborrecimento.

20 Cria condições para uma visão crítica da realidade e constrói com os alunos uma postura ética quanto à prática da futura profissão.

21 Gosta de ensinar e considera importante mseu trabalho.

22 É pontual quanto ao horário de aulas e demais compromissos.

23 Aproveita adequadamente o tempo de aula disponível.

24 Preocupa-se em relacionar os conteúdos trabalhados em aula com o contexto social.

25 Estimula o desenvolvimento do pensamento crítico/reflexivo do aluno.

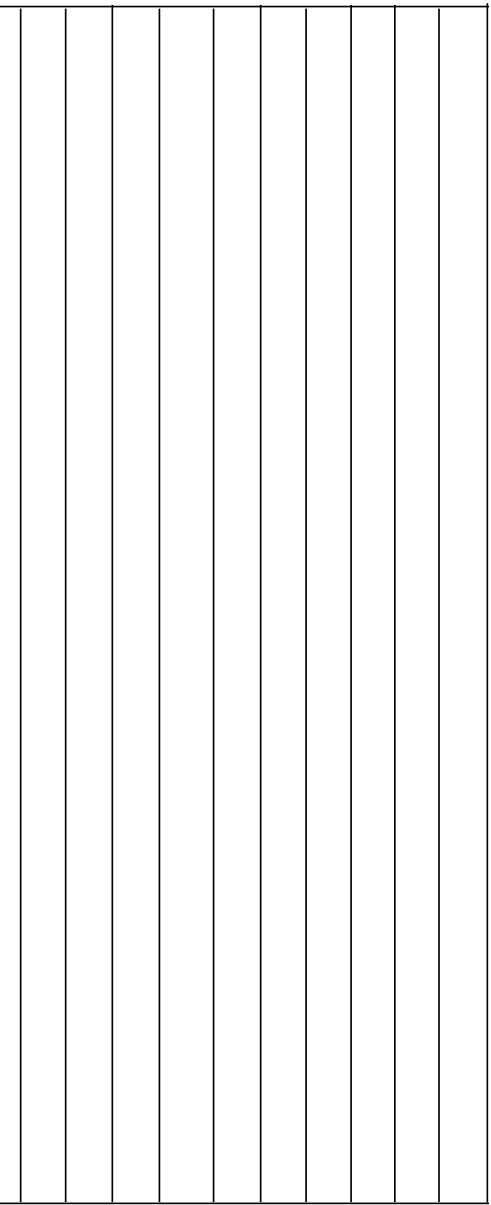




\section{ANEXO 3 - Auto-Avaliação de uma Instituição de Ensino na Perspectiva dos Aprendizes ${ }^{10}$}

Atribua a cada um dos aspectos da instituição uma nota de 1 a 10, assinalando com um "X" na coluna apropriada, de acordo com a escala abaixo:

Nota Inferior $1 \_$_ _ 3_4_5_6_ 7 _ 8_9_ 10 Nota Superior

Deixe em branco os itens que você não tiver condições de avaliar.

\begin{tabular}{|c|c|c|c|c|c|c|c|c|c|c|c|}
\hline & & & & & & & & & & & \\
\hline & & 1 & 2 & 3 & 4 & 5 & 6 & 7 & 8 & 9 & 10 \\
\hline 1 & $\begin{array}{l}\text { A Coordenação do Curso tem procurado } \\
\text { melhorar as condições de ensino- } \\
\text { aprendizagem? }\end{array}$ & & & & & & & & & & \\
\hline 2 & $\begin{array}{l}\text { O Coordenador do Curso está disponível e } \\
\text { aberto ao diálogo com os alunos? }\end{array}$ & & & & & & & & & & \\
\hline 3 & $\begin{array}{l}\text { O Coordenador atende os alunos com presteza } \\
\text { e atenção? }\end{array}$ & & & & & & & & & & \\
\hline
\end{tabular}

B - CPD (Centro de Processamento de Dados)

\begin{tabular}{|c|c|c|c|c|c|c|c|c|c|c|c|}
\hline & & 1 & 2 & 3 & 4 & 5 & 6 & 7 & 8 & 9 & 10 \\
\hline 1 & $\begin{array}{l}\text { Os equipamentos dos CPDs são suficientes para } \\
\text { todos os alunos? }\end{array}$ & & & & & & & & & & \\
\hline 2 & $\begin{array}{l}\text { Os equipamentos estão em boas condições de } \\
\text { manutenção? }\end{array}$ & & & & & & & & & & \\
\hline 3 & O sistema de impressão está satisfatório? & & & & & & & & & & \\
\hline 4 & $\begin{array}{l}\text { A assistência por parte dos monitores é } \\
\text { eficiente? }\end{array}$ & & & & & & & & & & \\
\hline 5 & $\begin{array}{l}\text { Os monitores tratam o aluno com atenção e } \\
\text { respeito? }\end{array}$ & & & & & & & & & & \\
\hline
\end{tabular}

\begin{tabular}{|c|c|c|c|c|c|c|c|c|c|c|c|}
\hline \multicolumn{12}{|c|}{$\mathrm{C}$-BIBLIOTECA } \\
\hline & & 1 & 2 & 3 & 4 & 5 & 6 & 7 & 8 & 9 & 10 \\
\hline 1 & Dispõe de livros e periódicos atualizados? & & & & & & & & & & \\
\hline 2 & Possui livros em número suficiente? & & & & & & & & & & \\
\hline 3 & $\begin{array}{l}\text { Dispõe de livros e outras publicações indicados } \\
\text { pelos professores? }\end{array}$ & & & & & & & & & & \\
\hline 4 & Proporciona bom atendimento? & & & & & & & & & & \\
\hline 5 & $\begin{array}{l}\text { Oferece instalações físicas satisfatórias para } \\
\text { estudo e consulta? }\end{array}$ & & & & & & & & & & \\
\hline
\end{tabular}

\footnotetext{
${ }^{10}$ Este instrumento foi aplicado numa Instituição de Ensino Superior localizada numa cidade de porte médio do sudeste brasileiro.
} 
D - SECRETARIA GERAL

\begin{tabular}{|l|l|l|l|l|l|l|l|l|l|l|l|}
\hline 1 & $\begin{array}{l}\text { O atendimento pela Secretaria Geral é } \\
\text { satisfatório quanto às informações solicitadas? }\end{array}$ & 1 & 2 & 3 & 4 & 5 & 6 & 7 & 8 & 9 & 10 \\
\hline $\begin{array}{l}\text { O atendimento pela Secretaria Geral é feito de } \\
\text { maneira atenciosa e educada? }\end{array}$ & & & & & & & & & & \\
\hline
\end{tabular}

E - SECRETARIA SETORIAL

\begin{tabular}{|c|c|c|c|c|c|c|c|c|c|c|c|}
\hline & & 1 & 2 & 3 & 4 & 5 & 6 & 7 & 8 & 9 & 10 \\
\hline 1 & $\begin{array}{l}\text { O atendimento pela sua Secretaria Setorial é } \\
\text { satisfatório quanto às informações solicitadas? }\end{array}$ & & & & & & & & & & \\
\hline 2 & $\begin{array}{l}\text { O atendimento pela sua Secretaria Setorial é feito } \\
\text { de maneira atenciosa e educada? }\end{array}$ & & & & & & & & & & \\
\hline
\end{tabular}

\section{F - INSTALACÕES FÍSICAS}

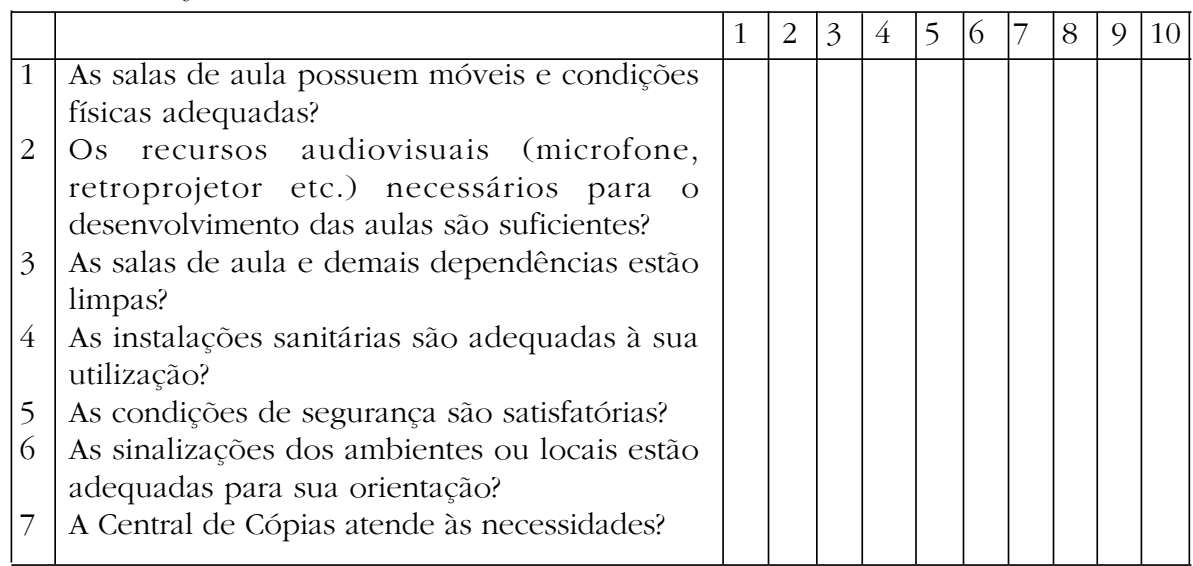

\section{G - CAE (Centro de Atendimento ao Estudante)}

\begin{tabular}{|l|l|l|l|l|l|l|l|l|l|l|l|}
\hline 1 & $\begin{array}{l}\text { O atendimento pelo CAE é satisfatório quanto } \\
\text { às informações? } \\
2\end{array}$ & $\begin{array}{l}\text { O atendimento pelo CAE é feito de maneira } \\
\text { atenciosa e educada? } \\
\text { O atendimento pelas telefonistas é satisfatório? }\end{array}$ & & & & & & & & &
\end{tabular}

$\mathrm{H}$ - TESOURARIA

\begin{tabular}{|l|l|l|l|l|l|l|l|l|l|l|l|}
\hline & & 1 & 2 & 3 & 4 & 5 & 6 & 7 & 8 & 9 & 10 \\
\hline 1 & O atendimento nos guichês é satisfatório? & & & & & & & & & & \\
2 & Os boletos são recebidos de forma regular? & & & & & & & & & \\
\hline
\end{tabular}

